\title{
A Educação Ambiental Crítica na formação inicial de licenciandos em Ciências Biológicas: contribuições e limitações
}

\author{
Critical Environmental Education in the initial training of licenses in Biological \\ Sciences: contributions and limitations
}

Carolina Borghi Mendes ${ }^{1}$

Marcia de Lourdes Spazziani²

\begin{abstract}
Resumo
Da observação da diversidade de ações carregadas de diferentes ideologias que vêm sendo desenvolvidas como Educação Ambiental (EA), o presente trabalho se propõe a apresentar dados e reflexões sobre uma disciplina de EA, pautada na vertente crítica, desenvolvida num curso de Licenciatura em Ciências Biológicas, a partir de uma atividade realizada pelos licenciandos e sua relação com as aulas. Pauta-se no Materialismo Histórico-Dialético enquanto fundamento teórico-metodológico e caracteriza-se como uma pesquisa qualitativa de intervenção educativa, em que a docente é também pesquisadora. Notou-se que a EA Crítica enquanto perspectiva teórica e metodológica da disciplina contribuiu com formação inicial dos professores/educadores ambientais para que possam realizar um trabalho docente sólido e a práxis coerente com a busca da transformação social, ainda que tenham existido limitadores objetivos nesse processo educativo, revelando a estreita relação entre o contexto educacional e as relações
\end{abstract}

\footnotetext{
${ }^{1}$ Doutoranda e Mestre pelo Programa de Pós-Graduação em Educação para a Ciência, Faculdade de Ciências, Universidade Estadual Paulista Júlio de Mesquita Filho (UNESP), Bauru/SP e graduada em Licenciatura em Ciências Biológicas pela mesma instituição. Integrante do Grupo de Pesquisa em Educação Ambiental (GPEA), vinculado ao mesmo Programa de Pós-Graduação, e do Grupo de Estudos e Pesquisa em Educação Ambiental, Sustentabilidade e Ambientalização (GEPEASA). Atualmente é Professora Colaboradora nas disciplinas de Didática, Políticas Públicas Educacionais e Metodologia e Prática de Ensino de Ciências, do Colegiado de Ciências Biológicas,Centro de Ciências Humanas e da Educação na Universidade Estadual do Norte do Paraná (UENP), campus Jacarezinho/PR. E-mail: carolina.mendes@uenp.edu.br.

${ }^{2}$ Possui graduação em Ciências Biológicas e Pedagogia. Mestrado em Educação pela Universidade Federal do Rio de Janeiro (1990), doutorado em Educação pela Universidade Estadual de Campinas (1999) e pós-doutoramento em Educação Ambiental pela ESALQ/USP (2002). Atualmente é professor assistente doutor da Universidade Estadual Paulista Júlio de Mesquita Filho, Câmpus de Botucatu, e credenciada no PPG Educação em Ciência do Câmpus de Bauru. Atua na formação de professores e educadores ambientais e desenvolve estudos na área de Educação Ambiental, Ensino da Saúde e Ensino de Ciências, com ênfase teórico-metodológico da psicologia histórico-cultural. E-mail: lurdinha@reitoria.unesp.br.
} 
sociais mais amplas, apontando-se para a necessidade de repensar, continuamente, o ensino superior.

Palavras-chave: Educação Ambiental Crítica. Formação Docente. Formação Inicial em Ciências Biológicas. Educação Superior.

\begin{abstract}
From observing the diversity of actions charged with different ideologies that have been developed as Environmental Education (Educação Ambiental -EA), the present work is based on data and reflections on an Environmental Education discipline. It is based on Historical-Dialectical Materialism for the theoretical-methodological foundation and characterization as a qualitative research of educational intervention, in which the teacher is also a researcher. It was noted that the Critical EA while the theoretical and methodological perspective of the discipline contributed to the initial formation of environmental teachers / educators so that they can carry out a solid work of teachers and the consistent practice with the search of a social transformation, although it has a limit of resources for the educational development, revealing a close relation between the educational context and as social relations more broadly, pointing to the need to continually rethink higher education.
\end{abstract}

Keywords: Critical Environmental Education. Teacher Training. Initial Formation in Biological Sciences. College education.

\title{
Introdução
}

A institucionalização da EA, no Brasil, se fez permeada por uma vasta diversidade de correntes político-pedagógicas, coerente com o amadurecimento da área e com as transformações ocorridas na sociedade, em especial, no que se aplica à educação.

Apesar do aumento quanti e qualitativo das pesquisas, Loureiro (2012) relembra a necessidade de ainda dissertarmos sobre o tema, já que “conceitos e categorias teórico-metodológicas passaram a ser tão comuns e recorrentes na fundamentação dos projetos, programas e ações que se esvaziaram de sentido" (LOUREIRO, 2012, p. 23).

As pesquisas e discussões sobre a Educação Ambiental (EA), atreladas aos problemas socioambientais, ganharam ainda mais destaque nas últimas décadas em virtude do grau de comprometimento dos recursos naturais, mas também da necessidade de construção de um processo civilizatório que assegure a humanidade (MARQUES, 2015). Neste sentido, a educação, em 
especial a escolar, se faz fundamental como forma de contribuir para a construção de práticas sociais críticas e emancipatórias (SPAZZIANI, 2017).

Com a Lei de Diretrizes e Bases da Educação, de 1996, tivemos a elaboração dos Parâmetros Curriculares Nacionais (PCNs), como guia curricular para disciplinas e ciclos escolares e, neles, a formulação dos eixos transversais, em que são abordados temas considerados urgentes "como a violência, a saúde, o uso de recursos naturais, os preconceitos", que não têm sido contemplados pelas grandes áreas do conhecimento (BRASIL, 1997, p. 23). Ainda nessa mesma década, houve a promulgação da Politica Nacional de Educação Ambiental (PNEA), Lei nº 9795, de 27 de abril de 1999, que em seu artigo $3^{\circ}$, inciso I, especifica que cabe "ao Poder Público, nos termos dos arts. 205 e 225 da Constituição Federal, definir politicas públicas que incorporem a dimensão ambiental, promover a educação ambiental em todos os niveis de ensino" (BRASIL, 1999).

Esse cenário se configurou como a prerrogativa inicial para a efetiva inserção da EA no ambiente escolar. Um estudo realizado pelo Ministério da Educação em parceria com a UNESCO, intitulado "O que fazem as escolas que dizem que fazem Educação Ambiental” (BRASIL, 2007) proporciona um importante panorama da Educação Ambiental nas instituições educacionais brasileiras. Quantitativamente, houve uma expansão significativa da EA nas escolas entre 2001 e 2004, de 115 mil escolas $(61,2 \%$ do total de escolas pesquisadas) para 152 mil (94\%). Dentre as modalidades de EA realizadas, o estudo aponta os projetos, as disciplinas especiais e a inserção da temática ambiental nas disciplinas. Nota-se, ainda, que a motivação inicial para o desenvolvimento da EA é, majoritariamente, de um professor ou de um grupo de professores. No entanto, Souza (2014) aponta que muitos professores não se sentem capacitados para atuarem na EA ou, então, acabam por desenvolver atividades pontuais, fragmentadas e descontextualizadas, dados também corroborado por Tozoni-Reis et al. (2013).

Dentre as principais dificuldades encontradas para essa inserção da EA na escola podemos destacar a rigidez dos conteúdos curriculares, a 
ausência de práticas pedagógicas ativas e contextualizadas e os deficitários programas de formação de professores (MENDES et al., 2016). Isso nos coloca a reflexão de que a formação inicial docente em EA representa a condição e, ao mesmo tempo, uma das limitações para que a Educação Ambiental seja desenvolvida na escola e pela escola, a fim de que esta não precise se submeter a inserções de instituições externas ao contexto escolar que em geral reproduzem um discurso ou uma determinada ideologia e descaracterizam a escola de sua função (MENDES, 2015).

Por isso, defendemos a importância da EA escolar desenvolvida pelos próprios professores, por serem estes os responsáveis pela atividade mediadora que:

[...] ultrapassa a relação aparente entre coisas, penetrando na esfera das intervinculações entre as propriedades essenciais das coisas. Ao introduzir o conceito de mediação, Vygotski, como procuramos evidenciar, não a tomou simplesmente como "ponte", "elo" ou "meio" entre coisas; tal como muitas vezes referido por seus leitores não marxistas. Para ele, a mediação é interposição que provoca transformações, encerra a intencionalidade socialmente construída e promove desenvolvimento; enfim, uma condição externa que, internalizada, potencializa o ato de trabalho, seja ele prático ou teórico (MARTINS, 2015, p. 47, grifos da autora).

No sentido, a formação inicial de professores que poderão atuar como educadores ambientais merece reflexão quanto à fundamentação que a norteia. Não há unanimidade sobre como desenvolver o ensino em EA, condizente com as divergências epistemológicas do campo. No entanto, a pluralidade que se apresenta à EA não deve ser entendida como neutralidade inerente à área ou como falta de necessidade de delineamento teórico-metodológico sobre a prática pedagógica. Ao contrário, se ao tratarmos da educação escolar devemos esclarecer qual seu papel, ao adentrarmos na EA precisamos definir quais nossas compreensões, objetivos e fundamentações, tanto para atividades e projetos desenvolvidos nas escolas, quanto para refletirmos sobre a formação de professores no ensino superior, pois a EA é, antes de qualquer coisa, um processo educativo. 
Evidenciar as diferentes perspectivas que configuram a EA é o ponto de partida para o presente trabalho, que tem como objetivo trazer discussões acerca das contribuições e limitações de uma disciplina de EA, pautada na vertente Crítica, à formação de licenciandos em Ciências Biológicas, numa universidade pública.

\section{Referencial teórico}

Coerente com nossa defesa sobre o papel da educação escolar, a qual deve socializar os conhecimentos produzidos historicamente pelo conjunto da humanidade (SAVIANI, 2012), possibilitando aos indivíduos as condições para o enfrentamento das principais questões colocadas à sociedade atual (MAIA, 2015), fundamentamos nossa ação docente na EA Crítica, perspectiva que se coloca a favor de uma educação transformadora ao buscar a construção de sociedades socialmente justas e ecologicamente equilibradas (TOZONI-REIS, 2012). Compreendemos que:

[...] o papel da educação é soberano, tanto para elaboração de estratégias apropriadas e adequadas para mudar as condições objetivas de reprodução, como para a automudança consciente dos indivíduos chamados a concretizar a criação de uma ordem social metabólica radicalmente diferente. [...]. Portanto, não é surpreendente que na concepção marxista a "efetiva transcendência da autoalienação do trabalho" seja caracterizada como uma tarefa inevitavelmente educacional (MÉSZÁROS, 2008, p. 65, grifos do autor).

Nesse sentido, a EA Crítica apresenta-se como uma educação política e não neutra, desenvolvida em oposição às vertentes conservadoras de EA que se pautam em abordagens e práticas reducionistas e comportamentalistas (LAYRARGUES; LIMA, 2011).

Tratando-se de educação, devemos compreender que não é qualquer processo educativo que se coloca comprometido com a transformação social; tão pouco que qualquer EA contribua com a formação de indivíduos para buscarem esse objetivo. Diversos autores (TOZONI-REIS, 2012; SAUVÉ, 2005; BRÜGGER, 1994; LAYRARGUES; LIMA, 2011) discorrem sobre isso. 
Segundo Layrargues e Lima (2011), diferentes são as vertentes teóricometodológicas e as perspectivas epistemológicas que fundamentam a EA. De maneira sintética, os autores discorrer sobre três principais, sendo elas a Conservacionista, a Pragmática e a Crítica.

A vertente Conservacionista originou-se no Brasil entre as décadas de 1970 e 1980, pautada em concepções de EA oriundas do contexto europeu. Caracteriza-se como ingênua e naturalista por basear-se nos conceitos ecológicos, com ênfase na dimensão afetiva do homem pela natureza e tendo como premissas a mudança de comportamento individual e a realização de ações pontuais, que, por vezes, se apresentam como culpabilizadoras dos cidadãos comuns (LAYRARGUES; LIMA, 2011).

A Pragmática ganhou força no cenário nacional a partir de 1990, momento de mudança nas exigências de mercado e da disseminação de ideais atrelados ao Desenvolvimento Sustentável e ao Consumo Sustentável. Essa vertente possui características vinculadas à sociedade urbanoindustrial, como a preocupação com o lixo, reciclagem e coleta seletiva, atrelando tais questões ambientais às tecnologias limpas, ao eco trabalho, a gestão ambiental e a eco eficiência empresarial (próprias da economia verde). Devido a isso, pauta-se em ações pontuais, de caráter comportamentalista, mas recorrendo aos conhecimentos técnicos e científicos para buscar soluções, de tal forma que reforça a compreensão de que os problemas ambientais devem ser (e serão!) resolvidos exclusivamente pela ciência, tornando-os externos às relações sociais, politicas e econômicas que determinam, inevitavelmente, esses mesmos problemas na sociedade capitalista contemporânea. Na realidade, essa vertente se apresenta como uma reconfiguração da anterior, ambas entendidas como conservadoras, já que se baseiam "em ações individuais e comportamentais no âmbito doméstico e privado, de forma a - histórica, apolítica, conteudística, instrumental e normativa" (LAYRARGUES; LIMA, 2011, p. 7) e com isso "não superariam o paradigma hegemônico que tende a tratar o ser humano como um ente genérico e abstrato, reduzindo os humanos à condição de 
causadores e vítimas da crise ambiental, desconsiderando qualquer recorte social” (LAYRARGUES; LIMA, 2011, p. 7).

A vertente Crítica, por sua vez, considera as ações humanas no curso da história ao analisar os problemas socioambientais, atentando-se às dimensões política, econômica, social, cultural, por compreender que a problemática ambiental não pode ser descolada da realidade concreta. Explicita que a relação homem-natureza deve ser analisada de forma dialética, afinal, a sociedade e os problemas presentes nela são decorrentes da organização do conjunto dos homens e, portanto, deve ser pensada como síntese de múltiplas determinações. Por isso, se coloca comprometida com a transformação social como necessidade para a superação da crise ambiental (LAYRARGUES; LIMA, 2011; TOZONI-REIS, 2012).

Partindo dessas considerações iniciais nos posicionamos a favor da necessidade de uma formação inicial de professores numa perspectiva crítica para atuarem como educadores ambientais. Sabemos, no entanto, das barreiras teóricas e práticas que se inserem nesse campo, próprias das condições materiais e da formação acadêmica no Brasil (MAIA, 2005, p. 19), exigindo-nos entender que:

O Estado capitalista em que vivemos não tem possibilitado a realização de uma educação comprometida com a transformação social, e nem poderiamos esperar isto, em se tratando de uma sociedade estruturalmente desigual, mas tem também produzido toda ordem de reducionismos e dificuldades no que se refere a dois aspectos, necessariamente interligado: a formação dos educadores (inicial e continuada) e a produção das condições objetivas em que se realiza o magistério. Utiliza-se dessa forma da educação para a difusão da ideologia dominante, contando para tal intento, de intelectuais de mais baixo nivel (VIEIRA, 2008, p. 161).

Porém, defendemos que a educação escolar é um espaço de luta em constante construção, sendo possível o desenvolvimento de ações para o enfrentamento de suas contradições e comprometidas com a busca da transformação social. É com esse pressuposto que o presente artigo se coloca.

\section{Fundamentos metodológicos}


Tendo como fundamento teórico-metodológico o Materialismo Histórico-Dialético (MARX, 2011), apoiando-nos na Pedagogia HistóricoCrítica (SAVIANI, 2012), nos propomos a analisar alguns dados provenientes de uma atividade formativa proposta na disciplina de Educação Ambiental realizada no curso de graduação em Ciências Biológicas, numa universidade pública em Bauru/SP, ocorrida no segundo semestre de 2017, como recorte de uma pesquisa de doutorado.

Trata-se de uma pesquisa qualitativa de intervenção educativa em que a docente é também pesquisadora. Pode ser considerada como pesquisaação crítica, por estar ligada a projetos emancipatórios e autogestionários (THIOLLENT, 1987), tendo em vista propor mudanças na realidade concreta através de uma metodologia exploratória, com objetivos definidos no campo de atuação pelo pesquisador e pelos participantes.

A disciplina foi realizada com duas turmas, uma composta apenas por discentes de licenciatura do período noturno, e outra por discentes de licenciatura e bacharelado do período integral. A metodologia de ensino pautou-se em aulas expositivas, dialogadas, com a apresentação de histórico e contextualização da EA no cenário mundial e nacional, das vertentes político-pedagógicas de EA e dos diferentes espaços de atuação do biólogoeducador ambiental (escolas, empresas, organizações não governamentais e instituições públicas). Concentrou-se também em estudos dirigidos, leituras e discussões de artigos relacionados à temática e da Política Nacional de Educação Ambiental (PNEA), incitando, constantemente, os estudantes a refletirem e questionarem suas próprias concepções e opiniões sobre a EA e, consequentemente, remetendo-os a embasarem suas futuras ações como educadores ambientais.

Além disso, a disciplina foi estruturada para que os discentes pudessem elaborar atividades em grupos, como o desenvolvimento de um projeto de EA, com a possibilidade de orientações da docente com cada grupo, em diferentes momentos da execução. Não obstante, os licenciandos também realizaram atividades individuais, sendo o presente trabalho resultado do recorte de uma delas, aplicada no encerramento da disciplina. 
A atividade em questão foi estruturada como um questionário com cinco perguntas abertas, dando maior liberdade para os respondentes expressarem seus posicionamentos. A escolha de uma amostra dos estudantes que participaram da disciplina para compor a análise da atividade neste trabalho foi constituída por um integrante de cada um dos seis grupos de discentes organizados para elaboração de um projeto de EA, da turma de licenciandos. A escolha de cada um dos seis discentes se deu de forma aleatória e, neste artigo, serão nomeados de R1 a R6. Das cinco questões estruturadas, nos debruçaremos na análise de duas para este trabalho, sendo elas:

a) Considerando o que você compreendia sobre EA, como essa disciplina contribuiu para sua formação como futuro biólogo ${ }^{3}$ que poderá atuar como educador ambiental?;

b) Como e porque a EA pode se configurar como um instrumento para a transformação social?.

Nosso objetivo é apontar alguns elementos centrais que evidenciem como a disciplina de Educação Ambiental na perspectiva Crítica pôde contribuir com a formação docente, sem deixar de elucidar as limitações encontradas, evidenciando pontos necessários à reflexão da formação inicial de professores em EA. Para isso, nos pautamos nas colocações dos próprios licenciandos expressas na atividade descrita e na sua relação com o que foi abordado e discutido nas aulas. Apresentaremos algumas respostas na integra ou outras em trechos, para facilitar a leitura e compreensão das análises.

Todos os dados foram coletados com aceite dos discentes participantes através da assinatura do Termo de Consentimento Livre e Esclarecido para pesquisa. Afirmamos que as análises realizadas são de total responsabilidade das autoras, não representando a perspectiva ou posicionamento da universidade ou do departamento aos quais à disciplina ofertada está vinculada.

\footnotetext{
${ }^{3}$ Como a pesquisa de doutorado é composta por discentes de licenciatura e bacharelado, optamos por especificar a formação como biólogo, ao invés de apenas professor.
} 


\section{RESULTADOS E DISCUSSÕES}

\section{Compreensões criticas em Educação Ambiental}

Um dos conteúdos elencados para ser trabalhado no decorrer da disciplina se tratou da apresentação e diferenciação das variadas correntes político-pedagógicas em EA, com intuito "de desmistificar o senso-comum de que a práxis da Educação Ambiental é unidimensional e unívoca” (MENDES, 2015, p. 37). Foi escolhido para iniciar essa reflexão o artigo de Layrargues e Lima (2011) que discorre sobre três macrotendências (ou vertentes) principais em EA: a Conservacionista, a Pragmática e a Crítica. Apesar de outros autores se debruçarem na classificação das vertentes de EA nossa escolha pelo artigo supracitado se deu por considerarmos que ele, em particular, sintetiza e classifica as vertentes de maneira concisa, sem, com isso, descaracterizar o movimento histórico que permeou a disputa deste campo social (conceito, aliás, trazido pelos autores com referência a Pierre Bourdieu):

Ao mapear o estado da arte da Educação Ambiental no Brasil o artigo também revela as aparentes contradições da sociedade brasileira, quando constata a ocorrência simultânea do fortalecimento da economia de mercado que, em alguns contextos parece ser a única realidade visível; com a ampliação gradual de uma cultura pública que impulsiona os movimentos da sociedade civil, a consciência cidadã e o exercício de práticas políticas participativas, ainda que com limites e em uma posição não hegemônica no interior da sociedade (LAYRARGUES; LIMA, 2011, p.13).

Mais do que nos atermos à memorização das três macrotendências, a intenção de trabalhá-las no decorre da disciplina foi problematizar cada um delas, apontando as limitações encontradas, em especial na conservacionista e na pragmática para, então, compreendermos a importância da vertente Crítica na EA, que supera por incorporação as outras. Os trechos a seguir evidenciam esse pressuposto: 
R1: A disciplina me ajudou a conhecer e compreender a Educação Ambiental Crítica, para não ficar mais no modelo conservacionista e pragmático, querer sempre mais, ir mais longe [...].

R2: A disciplina me proporcionou uma expansão de horizontes, mostrando um panorama mais "profundo" e elaborado da educação ambiental, contribuiu de forma que, agora, podendo vir a ser uma educadora ambiental um dia, a visão de uma ação que poderia ser proposta por mim um dia, será algo muito além do pontual, pois agora eu entendo que em qualquer tema existem sempre muitas outras questões relacionadas para ser abordadas.

R5: [...] Ela [a EA Crítica] ${ }^{4}$ amplia a nossa visão. E nos faz entender que não se baseia apenas no "verde", mas sim, envolve tudo como economia, política, etc.

Outro ponto que merece destaque nas respostas se refere à compreensão dos discentes sobre a não neutralidade na EA a partir da compreensão dos diferentes objetivos e fundamentos que permeiam a área e se refletem nas ações desenvolvidas:

R3: [...] Eu seguia (sem perceber também) ações pontuais e jurava que o público mudaria e criaria até novos valores, no entanto, após a disciplina e ver as coisas num caráter mais crítico, passei a questionar até as estruturas das ONGs as quais participei. Digo: qual o real objetivo dela? Dessa forma, acho que a disciplina meu fez abrir os olhos para questões muito importantes que circundam a real problemática, não apenas seguir o sendo comum do "ecologicamente correto".

R6: Contribuiu porque como consequência compreendemos que existem diferentes vertentes na educação ambiental e que ações realizadas em nome disso nem sempre tem, ou quase nunca tem, realmente interesse em educar

\footnotetext{
${ }^{4}$ As autoras optaram por utilizar colchetes na complementação das frases dos discentes que foram recortadas, para maior compreensão sobre o que está sendo afirmado.
} 
ambientalmente e promover verdadeiras ações e sim outros objetivos não explícitos. Como educadora vou buscar sempre seguir a vertente crítica e englobar todos os elementos necessários para realizar minhas ações.

Durante as aulas abordamos a necessidade de questionarmos nossas ações de EA enquanto educadores ambientais e professores e, também, as ações de outros agentes que se inserem nesse campo - como empresas, órgãos públicos, organizações não governamentais (ONGs), etc. Diferentes estudos foram discutidos em sala para dar subsídios aos discentes sobre essas reflexões (MENDES, 2015; FOSSALUZA, 2015; LAYRARGUES, 2016). Mendes (2015) analisou a inserção de instituições externas à escola pública a partir da EA, apontando as consequências desfavoráveis ao ensino quando empresas, por exemplo, adentram o espaço escolar público. Por outro lado, afirma como as próprias empresas se beneficiam dessa inserção, algo corroborado por Layrargues (2016) quando discorre sobre os motivos reais da reciclagem de materiais de aluminio a partir do projeto de uma empresa desenvolvido em diferentes escolas. Fossaluza (2015), por sua vez, debruçouse na realização de um levantamento das ONGs Ambientalistas no estado de São Paulo, buscando compreender quais ações em EA eram praticadas e como as fontes de financiamentos podiam influenciar tais atividades e as concepções que as embasavam.

Nesse sentido, ao assumirmos que a educação em si - antes mesmo de a especificarmos como EA - é um ato político e ideológico, é necessário ressaltar que apesar das diferentes e, muitas vezes, contraditórias concepções sobre o processo educativo ambiental, nenhuma delas se configura neutra, conforme compreendido pelos discentes. Entendemos que a própria negação de um posicionamento ou falta de reflexão sobre os objetivos das ações se mostram atreladas a uma compreensão de mundo, não sendo possivel discutir sobre educação e atuar no campo educacional, inerentemente um campo de luta e conflitos sociais, sem assumir uma postura política (MENDES; TALAMONI, 2017): 
Esta ênfase nos aspectos políticos e ideológicos objetiva destacar o elemento que é característico da perspectiva crítica, para a qual a prática educacional expressa um compromisso político situado sócio historicamente que influencia na escolha e posicionamento por uma ou outra das concepções de EA. Ou seja, todas as perspectivas de educação possuem sustentação em determinada posição políticaideológica, ainda que os educadores tenham isso claro ou não (SOUZA, 2014, p. 31).

No trecho a seguir, R5 destaca dois pontos importantes que nos fazem refletir sobre a epistemologia da formação inicial desses licenciandos:

R5: Confesso que essa disciplina foi mais dificil do que eu imaginava. Não esperava que fosse tão complexa e difícil de colocar no papel. No entanto, ela fez com que "abramos" os olhos, e "enxergue" a realidade e do que realmente precisamos nela. Através dela [a disciplina], posso dizer que hoje de certo modo me torno mais crítica e espero que mais problematizadora [...] Apesar de algumas dificuldades, ela [a disciplina] realmente se fez essencial e fará diferença no meu olhar como bióloga.

O primeiro ponto que se evidencia é o da complexidade da disciplina e da dificuldade encontrada pelos discentes. Um dos elementos que justifica essa percepção é que apesar da EA ser amplamente debatida e praticada na sociedade e entre os licenciandos - muitos, no decorrer das aulas indicaram atuar em EA -, sua abordagem conservadora hegemônica resultou num estranhamento inicial dos discentes ao se depararem com a fundamentação crítica da EA na disciplina.

Outro elemento que chamou nossa atenção foi o fato dos estudantes, provenientes de um curso das ciências naturais, terem escassa experiência em leituras de cunho teórico e pouquíssimo conhecimento sobre pesquisas de natureza qualitativa, o que se mostrou um complicador aos discentes e que, ao tratarmos da formação de professores, precisa ser repensado. Sabemos da predominância das pesquisas de natureza quantitativa no meio acadêmico das ciências naturais e exatas, bem como da hegemonia da lógica formal na ciência, devido ao modelo de ciência moderna ocidental: 
[...] pode-se verificar o equívoco do pensamento cartesiano, a crença na verdade científica absoluta. Hoje se sabe que não há verdade absoluta na ciência, a própria ciência evidenciou que em suas teorias e em seus conceitos há limitações, e é exatamente esse aspecto que permite o avanço da ciência atualmente (MAIA, 2015, p. 33).

Ao se depararem com uma abordagem critica, que relaciona dialeticamente o conhecimento das ciências naturais e humanas, os discentes se viram diante de novas formas de pensar e agir no campo científico. Esse movimento, próprio do processo de ensino comprometido com a elaboração do pensamento teórico, pode ser entendido como a elevação do conhecimento do senso comum à consciência filosófica (SAVIANI, 2013). Não se trata de negar a lógica formal, mas de compreendêla como um momento da lógica dialética que possibilita a construção do pensamento a partir da compreensão imediata do conhecimento empírico que através de abstrações e estabelecimento de relações, possibilita alcançar o conhecimento concreto da realidade:

Diferentemente, pois, da crença que caracteriza o empirismo, o positivismo, etc. (que confundem o concreto com o empírico) o concreto não é ponto de partida, mas ponto de chegada do conhecimento. E, no entanto, o concreto é também o ponto de partida. Como entender isso? Poder-se-ia dizer que o concreto-ponto de partida é o concreto real e o concreto-ponto de chegada é o concreto pensado, isto é, a apropriação pelo pensamento do realconcreto (SAVIANI, 2013, p. 4-5).

Apesar das dificuldades encontradas pelos discentes próprias do percurso formativo ao qual tiveram acesso até então, corroboramos Layrargues e Lima (2011, p. 13) ao afirmarem que "conhecimento e autoconhecimento sempre foram ingredientes indispensáveis à práxis, à transformação dos indivíduos em sujeitos, ao desenvolvimento social e a ampliação das liberdades humanas". Nesse sentido, com as discussões, leituras, atividades e com a mediação da docente no processo de ensino e aprendizagem, os estudantes se viram diante de uma mudança de paradigma, fazendo-os repensarem sua própria prática social e atuação 
como educadores, ainda que de forma pouco aprofundada pelo curtíssimo tempo disponivel à disciplina 5 .

\section{A EA Critica como um instrumento para a transformação social}

Saviani (2009) explicita um caminho metodológico para desenvolver a prática pedagógica em sala de aula articulada à realidade social, baseado em cinco momentos. Segundo ele, é preciso partir e retornar à prática social quando desenvolvemos um processo educativo, articulando-a aos conteúdos escolares.

Compreender a prática social inicial pressupõe fazer uma leitura da realidade concreta; o professor nesse momento tem o entendimento sintético ao compreender a realidade da sociedade em suas bases concretas e ter clareza dos objetivos do ensino, mas ainda de forma precária, já que num movimento dialético com seus educandos continuará reelaborando sua compreensão. Os educandos, por sua vez, apresentam uma compreensão sincrética da realidade, ou seja, fragmentada, empírica, não conseguindo ainda articular o que estão aprendendo com a realidade, condição que se busca superar com problematizações sobre a prática social e com a instrumentalização através dos conhecimentos científicos.

Esse movimento de construção do conhecimento proporcionará a catarse, quando uma nova forma de entendimento da realidade se apresenta aos estudantes e também ao professor; é possivel estabelecer relações mais amplas e complexas sobre aquela prática social inicial, de tal forma que ao retornar a ela, os indivíduos se apresentam epistemologicamente diferentes do início do processo educativo, podendo compreender a realidade sinteticamente e, por isso, agir intencionalmente sobre ela.

Essa breve delineação se faz pertinente para analisarmos as respostas dos estudantes sobre as possibilidades da EA Crítica colaborar com a transformação da prática social e sobre como eles mesmos apresentaram

\footnotetext{
${ }^{5}$ Em outra questão da mesma atividade - que não está sendo analisada aqui - a maioria dos discentes apontou como o curto período da disciplina foi um complicador, pois ela tem um total de apenas 30 créditos, sendo 2 aulas por semana para cada turma, ou seja, 2 horas/aula.
} 
elementos que evidenciam o alcance da catarse, após o processo de ensino pautado em problematizações e instrumentalizações.

Nos trechos abaixo, os respondentes chamam atenção sobre a realidade do contexto e da vida social das pessoas envolvidas nas possiveis ações e problemáticas de EA, a partir da questão sobre ser esta um possivel instrumento para transformação social:

R4: A EA pode se configurar como um instrumento para transformação social, pois como a educação aplicada de uma maneira correta e coerente com a vida social do público como visto em aula. As pessoas vão conseguir entender o real motivo para 'estar' realizando tal ação, percebendo que uma coleta de recicláveis não é só separar um lixo e assim visando 'para melhor'.

R6: A educação ambiental, no momento em que segue a vertente crítica, pode ser um instrumento de transformação social porque vai buscar diferentes aspectos como histórico, cultural [...] verdadeiros objetivos serão formados de acordo com a verdadeira necessidade e realidade do contexto. No final de todas as ações, espera-se que ocorra a transformação social através desse instrumento que funciona como o da educação básica mesmo.

As explanações evidenciam a importância de considerar o contexto social dos envolvidos na proposição de ações de EA, uma preocupação discutida em diversos momentos durante as aulas. Ao iniciarmos as reflexões sobre os projetos de EA para a disciplina, um dos pressupostos elencado foi conhecer e considerar o contexto em que tais ações seriam propostas. De acordo com a EA Crítica, as ações precisam levar em consideração a realidade socioambiental do público-alvo, não podendo simplesmente ser uma ação estruturada e pensada de maneira genérica, mas exigindo do educador conhecer com quem e onde irá trabalhar para evitar ações pontuais, fragilizadas e que não se relacionam à prática social dos envolvidos. Alguns dos exemplos elucidados em aula foram: qual o impacto real, que vise à transformação social, se nós, educadores 
ambientais, elaboramos uma atividade sobre economia de água se, ao chegarmos à comunidade que desejamos desenvolver tal ação, verificamos que a problemática pertinente àquele contexto se refere ao lixo? Como falar sobre a importância de cada um economizar água se naquele contexto não há acesso à agua encanada e/ou tratada?

Essas reflexões se aplicam, também, na EA escolar, pois ao propor uma problematização ou atividade em EA, o professor precisa considerar que está trabalhando com estudantes que, antes de tudo, são indivíduos sociais, atrelados a uma realidade local, com características sociais e históricas:

\footnotetext{
Nessa concepção de educação, a abordagem dos conteúdos programáticos ou do conhecimento a serem construídos requer considerarmos, como importante recurso pedagógico, a realidade vivenciada por educadores e educandos em seus locais de estudo, moradia e trabalho, destacando-se a diversidade cultural e a exclusão social que caracterizam a sociedade (LOUREIRO et al., 2009, p. 89).
}

Durante a disciplina os alunos não tiveram acesso direto aos textos da Pedagogia Histórico-Crítica, no entanto, esta embasou as discussões da docente/pesquisadora e, por isso, em momentos específicos das aulas foi essencial nos reportarmos aos seus fundamentos. Isso é evidenciado na colocação da respondente R6, quando demonstra compreender que a EA é um processo educativo e sendo assim não transforma a realidade de forma direta e imediata, mas possibilita aos indivíduos compreenderem sua realidade contraditória e, com isso, atuarem como agentes sociais de transformação desta mesma realidade (SAVIANI, 2009). Os próprios discentes, ao se depararem com a vertente Crítica, questionavam o alcance imediato da educação e da EA na transformação social, o que exigia da docente explicar que o imediatismo não compete à educação (na perspectiva adotada), tão pouco à EA que se configura como um processo educativo, pois é determinado socialmente (SAVIANI, 2012) e, por isso, deve estar em constante análise e reconstrução. 
R1: [A EA] Transforma as pessoas em indivíduos críticos, capazes de analisar a fundo a questão em pauta, não apenas para benefício próprio, mas sim, indo muito além disso, para benefício de todos.

Sair da esfera individual se constitui como ponto fundamental para uma postura crítica e consciente diante da realidade. Proporciona estabelecer relações não antes compreendidas, de tal forma que a tematização do ambiente não pode mais se restringir a ações para o beneficio próprio, tão pouco acometem individualmente os seres humanos:

R2: A EA pode se configurar como um instrumento para transformação social por meio de práticas e conteúdos que construam uma mudança de atitude nas pessoas, fazendo com que ao abordar todas as questões relacionadas a determinado tema, o indivíduo consiga compreender a questão e se transformar. A transformação social não acontece rapidamente, mas mesmo que a passos lentos, pode sim acontecer.

R3: Como se trata da prática da educação, a EA dá subsídios para o público pensar de 'um outro' modo e talvez, na construção de novos valores. Dessa forma, a partir do momento em que o individuo passa a aplicar seus conhecimentos em sua ideia de mundo, é notável como a educação é indispensável para que seja atingida [a ideia de mundo].

R5: [...] Vejo que é mais dificil [do que esperava] e que não é fácil [atuar na EA]. E que não podemos abraçar o mundo. Mas que podemos através da EA crítica, atingir de modo mais radical as pessoas. Ou seja, de modo que nos tornamos mais críticos em busca dos nossos direitos e deveres.

Os trechos acima se complementam quando os analisamos tendo como foco a prática social transformada e o papel da educação nesse processo. Entendemos que a transformação social não é pontual ou súbita, mas exige comprometimento que só é possivel se os indivíduos compreenderem sua realidade e seus determinantes. Se o problema 
ambiental é o lixo, por exemplo, não adianta apenas prezar pela reciclagem se os sujeitos não compreenderem que o aspecto central dessa problemática é o consumo e as relações de mercado que produzem e reproduzem uma cultura consumista (LAYRARGUES, 2016). Nesse sentido:

\begin{abstract}
A Educação Ambiental, através de sua especificidade, ou seja, de sua preocupação com a situação geral (mundial) e particular (regional, local), atende e retoma as finalidades amplas da educação. Devemos relembrar que integram essa especificidade o atendimento de fatores que interferem nos problemas ambientais, sob aspectos econômicos, sociais, políticos e ecológicos; a aquisição de conhecimento, de valores, de atitude, de compromisso e de habilidade necessários para a proteção e melhoria do meio ambiente; a criação de novos padrões de conduta orientados para a preservação e melhoria da qualidade do meio ambiente (CASTRO; SPAZZIANI, 2000, p. 195-196).
\end{abstract}

No entanto, R4 ao afirmar que a EA se trata de "prática da educação", demonstra limitações sobre a compreensão deste campo, algo também demonstrado por outros discentes no decorrer da disciplina. Estabelecer que a EA seja a prática se deve, por um lado, a não superação da racionalidade prática e técnica que se perpetua na academia e também nas práticas pedagógicas das ciências naturais (DUARTE et al., 2009) e, por outro, pode estar relacionada à elaboração do projeto final da disciplina que, além de um estudo teórico aprofundado, exigia a proposição de uma ação prática de intervenção em EA - como atividades com alunos, professores, comunidades carentes, agricultores em assentamentos rurais, etc.

Em relação à colocação de R5, foi possível percebermos que o conhecimento sobre as vertentes político-pedagógicas da EA possibilitou uma mudança qualitativa na compreensão epistemológica da discente quando demonstra compreender a radicalidade da EA Crítica. Evidencia ser possivel, a partir dela, a superação das ações pontuais e descontextualizadas e a necessidade de desenvolver uma educação que leve em consideração à prática social. Não se trata de qualquer EA, mas a que instrumentalize os indivíduos para que conheçam os direitos e deveres relacionados às problemáticas ambientais. Por isso "somente a educação ambiental crítica tem condições de enfrentar e instrumentalizar os sujeitos para agirem de 
forma significativa e desempenharem seu papel de cidadão" (MAIA, 2015, p. 126).

Para isso, a formação do educador ambiental como mediador do processo de ensino e aprendizagem precisa estar comprometida com a compreensão da realidade em suas múltiplas determinações para que saiba relacionar as implicações do modelo de sociedade vigente ao ambiente. Esse é o pressuposto para que possa agir intencionalmente sobre a prática social e instrumentalizar seus alunos para também compreendê-la:

[...] um professor de história ou de matemática, de ciências ou estudos sociais, [...] etc. tem cada um uma contribuição específica a dar, em vista da democratização da sociedade brasileira, do atendimento aos interesses das camadas populares, da transformação estrutural da sociedade. Tal contribuição consubstancia-se na instrumentalização, isto é, nas ferramentas de caráter histórico, matemático, científico, literário etc., cuja apropriação o professor seja capaz de garantir aos alunos. Ora, em meu modo de entender, tal contribuição será tanto mais eficaz quanto mais o professor for capaz de compreender os vínculos da sua prática com a prática social global. Assim, a instrumentalização desenvolver-se-á como decorrência da problematização da prática social, atingindo o momento catártico que concorrerá na especificidade da matemática, da literatura etc., para alterar qualitativamente a prática de seus alunos como agentes sociais (SAVIANI, 2009, p.72).

Sabemos das limitações existentes em qualquer atividade, ação ou projeto de EA, algumas também percebidas pela docente/pesquisadora na disciplina analisada. No entanto, não podemos perder de vista que a educação é prática social (SAVIANI, 2012), produzida e repensada pelos seres humanos e que, portanto, deve estar em constante reelaboração condizente com os condicionantes e contradições da realidade que também se alteram. Isso implica repensarmos continuamente a formação no ensino superior na EA e nas demais áreas, pois suas determinações se relacionam a aspectos sociais mais amplos e, consequentemente, suas implicações refletem na organização da sociedade, seja para mantê-la como está posta ou para transformá-la.

\section{CONSIDERAÇÕES FINAIS}

Interfaces da Educ., Paranaíba, v.9, n.25, p. 154-178, 2018

ISSN 2177-7691 
A concepção da Educação Ambiental Crítica adotada como fundamentação para o desenvolvimento da disciplina no ensino superior, evidencia contribuições basais sobre o papel da formação inicial dos futuros profissionais, por ter colaborado para incorporar ao discurso dos sujeitos investigados importantes indícios de outro pensamento sobre o fazer educativo socioambiental na sociedade atual. Por outro lado, revela a estreita relação entre educação e cultura, relação que se fundamenta em métodos e análises que colocam em evidência as condições materiais e os processos culturais que ocorrem no seu interior. As relações educacionais - aqui expressas pelo ensino superior - são colocadas no âmbito das relações sociais amplas, aparecendo no ambiente escolar o mundo do trabalho, a relação com o ambiente natural e cultural dos participantes e suas possibilidades de vida, o contexto cultural de suas relações cotidianas, tudo relacionado ao contexto geral da sociedade.

Entretanto, temos uma educação que também foi idealizada e fundamentada nos ideais iluministas, priorizando a razão, o discurso científico (cientificista) como forma de aquiescer e instrumentalizar as capacidades intelectuais e cognitivas. Essa característica da educação escolar tem lhe destinado à função de reprodutora da ideologia dominante, portanto, sua inscrição, de um modo geral, é garantir a formação de cidadãos moralmente comprometidos com o projeto de sociedade burguesa e concretamente atuantes como individuos egoístas e independentes (SPAZZIANI, 2017), o que precisa ser repensado constantemente e enfrentado com clareza de fundamentação teórico-metodológica na formação inicial de professores.

A Educação Ambiental Crítica como proposta educativa que surge da consciência das limitações do processo civilizatório moderno é uma via que expressa, fundamentalmente, a contestação ao modelo de exploração do ambiente natural e, consequentemente, do ambiente social da vida moderna, podendo ser um instrumento formativo importante no ensino superior. 


\section{Referências}

BRASIL. Secretaria da Educação Fundamental. Parâmetros Curriculares Nacionais: apresentação dos temas transversais. Brasília, DF: MEC/SEF, 1997.

BRASIL. Politica Nacional de Educação Ambiental. Lei 9.795, de 27 de abril de $1999 . \quad$ Disponivel em: <http://www.planalto.gov.br/ccivil_03/Leis/L9795.htm>. Acesso em: 15 dez. 2017.

BRASIL. Ministério da Educação. Secretaria de Educação Continuada, Alfabetização e Diversidade. Educação na diversidade: o que fazem as escolas que dizem que fazem educação ambiental? TRABJER, R.; MENDONÇA, P. R. (Orgs.). Brasília: MEC/SECAD, Coleção Educação para Todos, Série Avaliação, n. 6, v. 23, 2007.

BRÜGGER, P. Educação ou adestramento ambiental? Florianópolis, SC: Letras Contemporâneas. 1994.

CASTRO, R. S.; SPAZZIANI, M. L. Contribuições de Piaget e Vygotsky a Educação Ambiental. In: NOAL, F.; CASTRO, R. S.; REIGOTA, M. Tendências da Educação Ambiental Brasileira. Santa Maria, SC: UNISC, 2000. p. 21-31.

DUARTE, M. S. et al. Perspectivas para além da racionalidade técnica na formação de professores das ciências. In: VII Encontro Nacional de Pesquisa em Educação em Ciências (ENPEC), Florianópolis, 2009. Anais... Florianópolis, 2009, p. 1-11. Disponivel em: < http://posgrad.fae.ufmg.br/posgrad/viienpec/pdfs/novo_07.pdf>. Acesso em 12 de fev. 2018.

FOSSALUZA, A. S. As ações em Educação Ambiental realizadas por Organizações Não-Governamentais no Estado de São Paulo: alcances e limitações. 2015. 206f. Dissertação (Mestrado em Educação para a Ciência) Programa de Pós-graduação em Educação para a Ciência, Faculdade de Ciências/UNESP, Bauru, 2015. Disponivel em: < https:/ / repositorio.unesp.br/handle/11449/77029/discover?field=author\&f 
iltertype_0=subject\&filter_0=Educa\%C3\%A7\%C3\%A3o+ambiental\&filter_rela tional_operator_0=equals\&filtertype=author\&filter_relational_operator=equal s\&filter=Fossaluza\%2C+Andr\%C3\%A9+Santachiara+\%5BUNESP\%5D>.

Acesso em: 20 de nov. 2017.

LAYRARGUES, P. P.; LIMA, G. F. C. Mapeando as macro-tendências políticopedagógicas da educação ambiental contemporânea no Brasil. In: VI Encontro de Pesquisa em Educação Ambiental (EPEA), Ribeirão Preto, 2011. Anais... Ribeirão Preto, 2011, p. 1-15. Disponivel em: <http://www.icmbio.gov.br/educacaoambiental/images/stories / biblioteca/e ducacao_ambiental/Layrargues_e_Lima_-_Mapeando_as_macrotend\%C3\%83\%C2\%AAncias_da_EA.pdf>. Acesso em: 15 de jan. 2018.

LAYRARGUES, P. P. O cinismo da reciclagem: o significado ideológico da reciclagem da lata de alumínio e suas implicações para a educação ambiental. In: LOUREIRO, C.F.B.; LAYRARGUES, P.P.; CASTRO, R. de S. (Orgs.) Educação ambiental: repensando o espaço da cidadania. São Paulo: Cortez, 2002. p. 179-219.

LOUREIRO, C. F. B. Trajetória e fundamentos da educação ambiental. São Paulo: Cortez, 2012.

LOUREIRO, C. F. B. Contribuições da teoria marxista para a educação ambiental crítica. Cad. CEDES [online], v. 29, n.77, p.81-97, 2009. Disponivel em: < http://www.scielo.br/scielo.php?pid=S010132622009000100006\&script $=$ sci_abstract\&tlng=pt $>$. Acesso em: 10 de jan. 2018.

MAIA, J. S. Educação Ambiental Crítica e formação de professores. $1^{\text {a }}$ ed. Curitiba, PR: Appris, 2015.

MARQUES, L. Capitalismo e Colapso Ambiental. Unicamp: Campinas, 2016. MARTINS, L. M. A internalização de signos como intermediação entre a Psicologia Histórico Cultural e a Pedagogia Histórico-Crítica. Germinal: Marxismo e Educação em Debate, Salvador, v. 7, n. 1, p. 44-57, jun. 2015. MARX, K. O Capital - Crítica da Economia Política. Livro I - Volume I. $28^{\circ}$ ed. Rio de Janeiro: Civilização Brasileira, 2011. 
MENDES, C. B. Influências de instituições externas à escola pública: privatização do ensino a partir da Educação Ambiental? 2015. 232f. Dissertação (Mestrado em Educação para a Ciência) - Programa de Pósgraduação em Educação para a Ciência, Faculdade de Ciências/UNESP, Bauru, 2015. Disponivel em: < http://www2.fc.unesp.br/BibliotecaVirtual/DetalhaDocumentoAction.do?id Documento=772>. Acesso em 20 de nov. 2017.

MENDES, C. B. et al. A inserção da educação ambiental nos cursos de formação de professores: transversalidade ou disciplinaridade? In: III Fórum de Educação Ambiental Crítica, 2016, Bauru. Anais... Bauru, 2016, p. 137141.

MENDES, C. B.; TALAMONI, J. L. B. A privatização do ensino a partir da educação ambiental: reflexões sobre relações público-privadas. Revista Trabalho, Politica e Sociedade, v. 2, n. 2, p. 65-82, jan. /jun. 2017.

MÉSZÁROS, I. A educação para além do capital. São Paulo: Boitempo Editorial, 2008.

SAUVÉ, L. Educação Ambiental: possibilidades e limitações. Educação e Pesquisa, v. 31, n. 2, p. 317-322, mai./ago. 2005.

SAVIANI, D. Escola e democracia. $41^{\text {a }}$ ed. Campinas, SP: Autores Associados, 2009.

SAVIANI, D. Pedagogia Histórico-crítica: primeiras aproximações. $11^{\mathrm{a}} \mathrm{ed}$. Campinas, SP: Autores Associados, 2012.

SAVIANI, D. Educação: do senso comum à consciência filosófica. $19^{\mathrm{a}}$ ed. Campinas, SP: Autores Associados, 2013.

SOUZA, D. C. A Educação Ambiental Crítica e sua construção na escola pública: compreendendo contradições pelos caminhos da formação de professores. 2014. 324f. Tese (Doutorado em Educação para a Ciência) Universidade Estadual Paulista, Faculdade de Ciências, Bauru, 2014. Disponível em:

<https://repositorio.unesp.br/bitstream/handle/11449/110907/00079570 8.pdf?sequence=1>. Acesso em: 18 de nov. 2017. 
SPAZZIANI, M. L. Ambientalização da Universidade: Desafios e aprendizagens da sustentabilidade em uma universidade. Tese de Livre Docência. Botucatu: Unesp, 2017.

THIOLlENT, M.. Notas Para o Debate Sobre Pesquisa-Ação. In: C. R. BRANDÃO (Org.), Repensando a Pesquisa Participante. $3^{\mathrm{a}}$ ed. São Paulo: Brasiliense, 1987. p. 82-103.

TOZONI-REIS, M. F. C. Princípios metodológicos da Educação Ambiental. In: Metodologias Aplicadas à Educação Ambiental. Curitiba, PR: IESDE, 2012. p. 33-45.

TOZONI-REIS, M. F. C. et al. Conteúdos curriculares da educação ambiental na escola: contribuições da pedagogia histórico-crítica. Em: VII Encontro de Pesquisa em Educação Ambiental (EPEA), 2013, Rio Claro, SP. Anais... Rio Claro, 2013, p. 1-13. Disponivel em: < http://www.epea.tmp.br/epea2013_anais/pdfs/plenary/0190-1.pdf>. Acesso em: 23 de fev. 2018. 